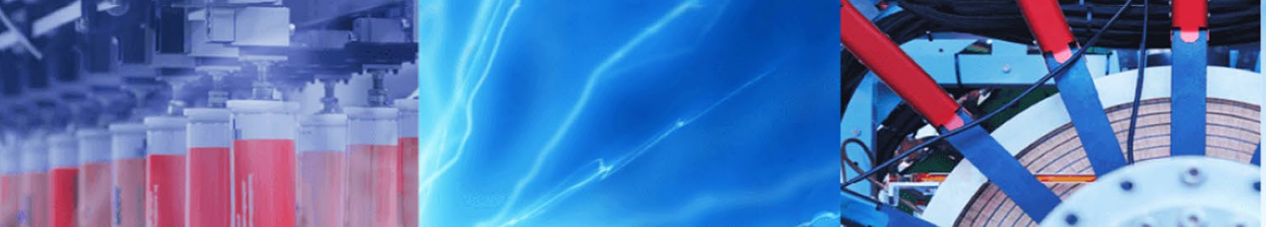

Research Article

\title{
Structural and electrical studies of PMMA and PVdF based blend polymer electrolyte
}

\author{
Venkata Ramana Jeedi ${ }^{1}$ E. Laxmi Narsaiah ${ }^{1} \cdot$ Mallaiah Yalla $^{2} \cdot$ R. Swarnalatha ${ }^{3} \cdot$ S. Narender Reddy ${ }^{4}$. \\ A. Sadananda Chary ${ }^{5}$
}

Received: 26 August 2020 / Accepted: 9 November 2020 / Published online: 27 November 2020

(c) Springer Nature Switzerland AG 2020

\begin{abstract}
PMMA-Poly Methyl Methacrylate, PVdF-Poly Vinylidene Fluoride and Silver Nitrate $\left(\mathrm{AgNO}_{3}\right)$ based blend polymer electrolytes have been prepared by solution cast method. DMF (Dimethyl Farmamide) was used as a common solvent. These systems have been characterized by Scanning Electron Microscopy, Fourier Transform IR Spectroscopy and X-ray Diffraction for various ratios of prepared solid polymer electrolytes. DC ion conductivity has been studied for prepared electrolyte systems and the ionic conductivity of these systems showed Arrhenius behavior. It has been found that the electrolyte membrane's ionic conductivity rises with temperature. AC conductivity, electric modulus and dielectric studies have been investigated. The enhancement of conductivity was observed to be maximum for $\mathrm{PMMA}(70 \%): \mathrm{PVdF}(30 \%): \mathrm{AgNO}_{3}(5 \%)$ $\left(9.13 \times 10^{-6} \mathrm{~S} / \mathrm{cm}\right)$ and is attributed to decrease in crystallinity.
\end{abstract}

Keywords Solution casting · XRD · FTIR · SEM - Ionic conductivity · Solid polymer electrolyte · Dielectric studies . Impedance analysis

\section{Introduction}

Solid polymer electrolytes (SPEs) have attracted significant attention due to their high energy density, and their applications are growing up at a quicker rate than that of any other compound electrolyte materials. SPEs provide certain unique advantages over electrolytes dissolved in organic solvents. These materials exhibit high mechanical strength and high ionic conductivity in the ambient environment, which resulted in remarkable interest for many researchers [1-3]. Polymer electrolytes are suitable for applications from a small-scale generation of sophisticated high energy density electrochemical devices, along with portable electronic devices like mobile phones, notebook computers, etc., to hybrid electric vehicles. Researchers have worked on several polymers like polyethylene oxide (PEO), polyvinyl pyrrolidone (PVP), polyvinyl chloride (PVC), etc., with salts like $\mathrm{LiClO}_{4}, \mathrm{Nal}, \mathrm{LiCF}_{3} \mathrm{SO}_{3}, \mathrm{NaClO}_{4}$, etc., to optimize electrical conductivity [4-6] and other properties. The maximum studies of polymer electrolytes have been performed on PEO matrix. Various approaches, such as co-polymerization, blending [7, 8], plasticization [9], and inorganic nanofillers [10] have been added to enhance the conductivity due to ions in the polymer electrolyte and its performance. By blending the chains of two or more polymers to form a network polymer, the electrical and structural properties can be improved [11-13]. Many researchers exemplified the ionic conductivity of blend polymer electrolyte systems by varying polymer ratios.

Among the polymers, PMMA has attracted good attention due to transparent, colorless, good life period, high mechanical, chemical stability and considerable

$\triangle$ A. Sadananda Chary, aschary60@gmail.com | 'Department of Physics, B V Raju Institute of Technology, Narsapur, Medak Dist 502313, India. ${ }^{2}$ Department of Physics, University PG College, Secunderabad, Osmania University, Hyderabad, India. ${ }^{3}$ Department of Physics, University College of Engineering (A), Osmania University, Hyderabad, India. ${ }^{4}$ Stanley College of Engineering and Technology for Women, Abids, Hyderabad, India. ${ }^{5}$ Department of Physics, University College of Science, Osmania University, Hyderabad, India. 
wettability and also has some drawbacks such as thermally low stability, low electrochemical stability and low cyclic rate performance. To overcome the disadvantages of electrolyte systems based on PMMA polymer, in the current work, the PMMA was blended with PVdF to achieve better performance of the electrolyte with improved electrochemical stability. There are two possible types of intermolecular interactions between PVdF and PMMA. One is hydrogen bonding between carbonyl groups of PMMA and methylene groups of PVdF. The other is a dipole-dipole interaction between methylene groups of PMMA and difluoromethylene groups of PVdF [14].

Therefore, it is appropriate to blend PMMA with PVdF. In the current research, blended polymer electrolyte systems with PMMA, PVdF and $\mathrm{AgNO}_{3}$ were prepared using solution casting technique. This study aims to investigate the ionic conductivity and dielectric properties of the prepared solid blend polymer electrolytes.

\section{Experimental procedure}

\subsection{Base materials}

Commercially available polymers, PVdF (avg $M_{W}=2,75,000$ ), PMMA (avg $M_{W}=1,20,000$ ), and Silver Nitrate $\left(\mathrm{AgNO}_{3}\right.$ 99.0\%) have been procured from Sigma Aldrich, India. The solvent N-N Dimethylformamide (DMF, 99.5\%) was obtained from MERCK. Before being used in the preparation of SPE films, they were dried in hot air.

\subsection{Preparation}

Solution cast method is the easiest way to render the samples with wide surface area. PMMA and PVdF host polymers were dissolved in $50 \mathrm{ml} \mathrm{DMF}$ in a suitable ratio. The solution was stirred at $350 \mathrm{rpm}$ on a hot plate magnetic stirrer at $50^{\circ} \mathrm{C}$ for $4 \mathrm{~h}$. Silver nitrate was slowly transferred into the polymer solution and continued the stirring for $24 \mathrm{~h}$ until it formed a homogeneous solution. The resulting suspension has been poured on a petri dish and dried in a vacuum oven for $36 \mathrm{~h}$ at $50^{\circ} \mathrm{C}$. A thick brownish colored SPE films were formed in accordance with [(1x) \% PMMA + (x)\% PVdF] (equivalent to $1 \mathrm{~g}$ weight) and
5 wt $\%$ of $\mathrm{AgNO}_{3}$ (where $\mathrm{x}=10,20,30$ and 40). Finally, the prepared films were coded as shown in Table 1 and stored in desiccators.

\subsection{Characterization}

XRD was carried out for pure $\mathrm{AgNO}_{3}$ and blend polymer electrolyte systems by XRD-700 X-Ray Diffractometer (SHIMADZU) with Cu-Ka radiation ( $\left.\lambda=1.5418 \mathrm{~A}^{\circ}\right)$ in the range $2 \theta=15-60^{\circ}$ at ambient environment. FTIR investigation was carried out for blended polymer electrolytes between 400 and $4000 \mathrm{~cm}^{-1}$ by FTIR-8400S (SHIMADZU). SEM analysis for the samples carried out by S-3700 N (HITACHI) up to optical magnification $50.0 \mathrm{KX}$. The impedance analysis was carried out for the prepared films at various temperatures in the frequency range of $100 \mathrm{~Hz}-30 \mathrm{MHz}$ by Impedance Analyzer PSM-1735 (N4L).

\section{Results and discussion}

\subsection{X-ray diffraction (XRD)}

XRD patterns of pure $\mathrm{AgNO}_{3}$, pure PMMA, pure $\mathrm{PVdF}$, different wt $\%$ ratios of PMMA and PVdF with constant $\mathrm{AgNO}_{3}(5 \mathrm{wt} \%)$ are shown in Fig. 1. A very high intense and sharp peak was observed at $40.20^{\circ}$ indicating a highly crystalline form of pure $\mathrm{AgNO}_{3}$ and several other low-intensity salt peaks at $19.5^{\circ}, 21.8^{\circ}, 24.2^{\circ}, 29.6^{\circ}, 32.7^{\circ}$, $35.6^{\circ}$ and $38.9^{\circ}$ affirm its extremely crystalline nature as notified in the literature [15]. The $\beta$ phase of PVdF crystal peak at $20.22^{\circ}$ and $\alpha$ phase peak at $38.8^{\circ}$ was observed in accord with the earlier results [16]. From figure, it was clearly noticed that no characteristic peaks were observed for pure PMMA which confirms the amorphous nature. Except a very low intense peak around $38^{\circ}$, all other peaks could not be recorded in the polymer blend electrolytes. The peak corresponding to $\beta$ phase of PVdF was drastically depressed and the position slightly shifted $[17,18]$ as PVdF wt\% increased. The peak broadening increased and shifted slightly towards lower angles, indicating that the association among the polymer chains contributes to a decline in the inter-molecular interaction between polymer chains. This resulting in
Table 1 Sample composition, codes, parameters obtained by XRD and crystallite sizes of samples

\begin{tabular}{lllll}
\hline $\begin{array}{l}\text { Sample composition } \\
\text { (with weight \%) }\end{array}$ & Sample code & $2 \theta$ (Degree) & $\begin{array}{l}\text { FWHM } \\
\text { (Degree) }\end{array}$ & Crystallite size $\left(\mathrm{A}^{\circ}\right)$ \\
\hline $90 \% \mathrm{PMMA}+10 \% \mathrm{PVdF}+5 \% \mathrm{AgNO}_{3}$ & $\mathrm{PPA} 1$ & 38.254 & 0.4723 & 178.062 \\
$80 \% \mathrm{PMMA}+20 \% \mathrm{PVdF}+5 \% \mathrm{AgNO}_{3}$ & $\mathrm{PPA} 2$ & 38.346 & 0.5323 & 158.035 \\
$70 \% \mathrm{PMMA}+30 \% \mathrm{PVdF}+5 \% \mathrm{AgNO}_{3}$ & $\mathrm{PPA} 3$ & 38.1697 & 0.6298 & 133.498 \\
$60 \% \mathrm{PMMA}+40 \% \mathrm{PVdF}+5 \% \mathrm{AgNO}_{3}$ & $\mathrm{PPA} 4$ & 38.3466 & 0.5372 & 156.594 \\
\hline
\end{tabular}




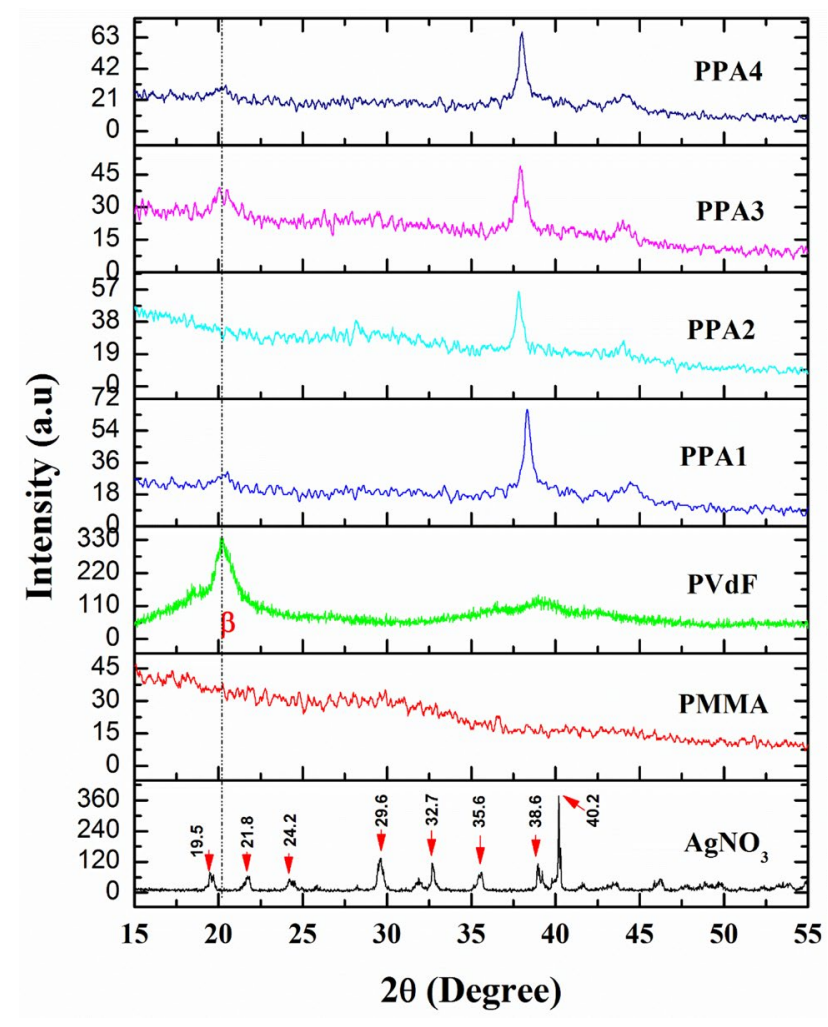

Fig. 1 XRD patterns of pure $\mathrm{AgNO}_{3}, \mathrm{PMMA}, \mathrm{PVdF}$ and blend polymer electrolyte systems

an improvement in the amorphous nature of the blend polymer electrolyte systems. Such quantitative differences in the crystal process support ion-dipole interactions in the (1-x)\% PMMA + (x)\% PVdF + 5\% $\mathrm{AgNO}_{3}$ membranes are heavily affected by the compositional weight ratios of the polymers in their blends for the preparation of various solid blend polymer electrolyte systems. This promotes the significant movement of polymer chains in the amorphous phase and the blended polymer electrolytes have undergone a systematic structural reorganization. The diffraction peak intensity decreased gradually and the least was observed for PPA3. The crystallite size of different polymer ratios was calculated using Sherrer's formula [19], $d=\frac{0.89 \lambda}{\beta \cos \theta}$, where " $\lambda$ " is the wavelength of monochromatic $\mathrm{X}$-ray beam (Cu-Ka radiation $\left.=1.5418 \mathrm{~A}^{\circ}\right), \beta$ is the full-width half maxima (FWHM) and $2 \theta$ is the angle of diffraction. The calculated values of the crystallite size of different samples were recorded in Table 1. The size of crystallite decreases with the decrease in PMMA percentage and the least was observed for PPA3 sample, which infers the increase in amorphous nature due to structural reorganization [20].

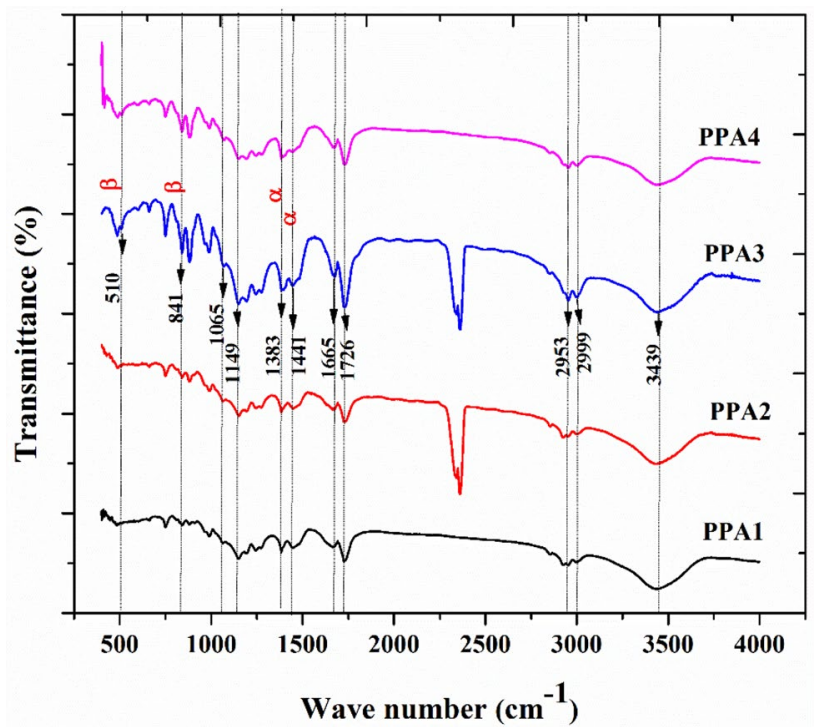

Fig. 2 FT-IR analysis of PPA1, PPA2, PPA3 and PPA4 samples

\subsection{Fourier transform IR Spectroscopic analysis}

Fourier Transform IR spectra of blend polymer electrolyte systems are shown in Fig. 2. The vibrational bands related to the $a\left(1441 \mathrm{~cm}^{-1}\right.$ and $\left.1383 \mathrm{~cm}^{-1}\right)$ and $\beta\left(841 \mathrm{~cm}^{-1}\right.$ and $510 \mathrm{~cm}^{-1}$ ) phase crystals of the innate PVDF are exhibited and assigned in the literature [21-23]. The absorption bands observed at $1726 \mathrm{~cm}^{-1}$ [24] are associated with $C=0$ stretching of carbonyl group belonging to PMMA polymer. Another absorption band at $2953 \mathrm{~cm}^{-1}$ compared to that of symmetric oscillations of PVdF $[25,26]$ and $3439 \mathrm{~cm}^{-1}$ corresponds to $\mathrm{N}-\mathrm{H}$ stretching (medium). The absorption peaks at $1665 \mathrm{~cm}^{-1}, 1441 \mathrm{~cm}^{-1}, 2999 \mathrm{~cm}^{-1}$ and $1065 \mathrm{~cm}^{-1}$ are related to $\mathrm{C}=\mathrm{C}$ stretching, $\mathrm{C}-\mathrm{H}$ bending (medium), strong $\mathrm{N}-\mathrm{H}$ stretching and $\mathrm{C}-\mathrm{O}$ stretching bonds respectively [27]. All the peaks have been shifted slightly [28] with loading of PVdF and a significant shift was observed for PPA3, which indicate the complexation of blend polymer with $\mathrm{AgNO}_{3}$. These observations in the FTIR spectra specifically indicates the variations in the polymer-polymer associations as well as conjugated PMMA and PVDF chain frameworks developed by coordination among ion and dipole in these electrolyte films.

\subsection{Scanning electron microscopy (SEM)}

Figure 3 demonstrates the SEM morphological images of PPA1, PPA2, PPA3and PPA4 samples. The white spots seen in PPA1 (Fig. 3a) could be due to presence of $\mathrm{AgNO}_{3}$ crystallites. The film's morphology changed substantially after PVDF was added with different weight percentages. The surface of PPA2 (Fig. 3b) appear to be non-uniform 
Fig. 3 SEM morphological images of (a) PPA1, (b) PPA2, (c) PPA3, (d) PPA4 at $10 \mathrm{KX}$ magnification and (e) PPA3, (f) PPA3 at $50 \mathrm{KX}$ magnification
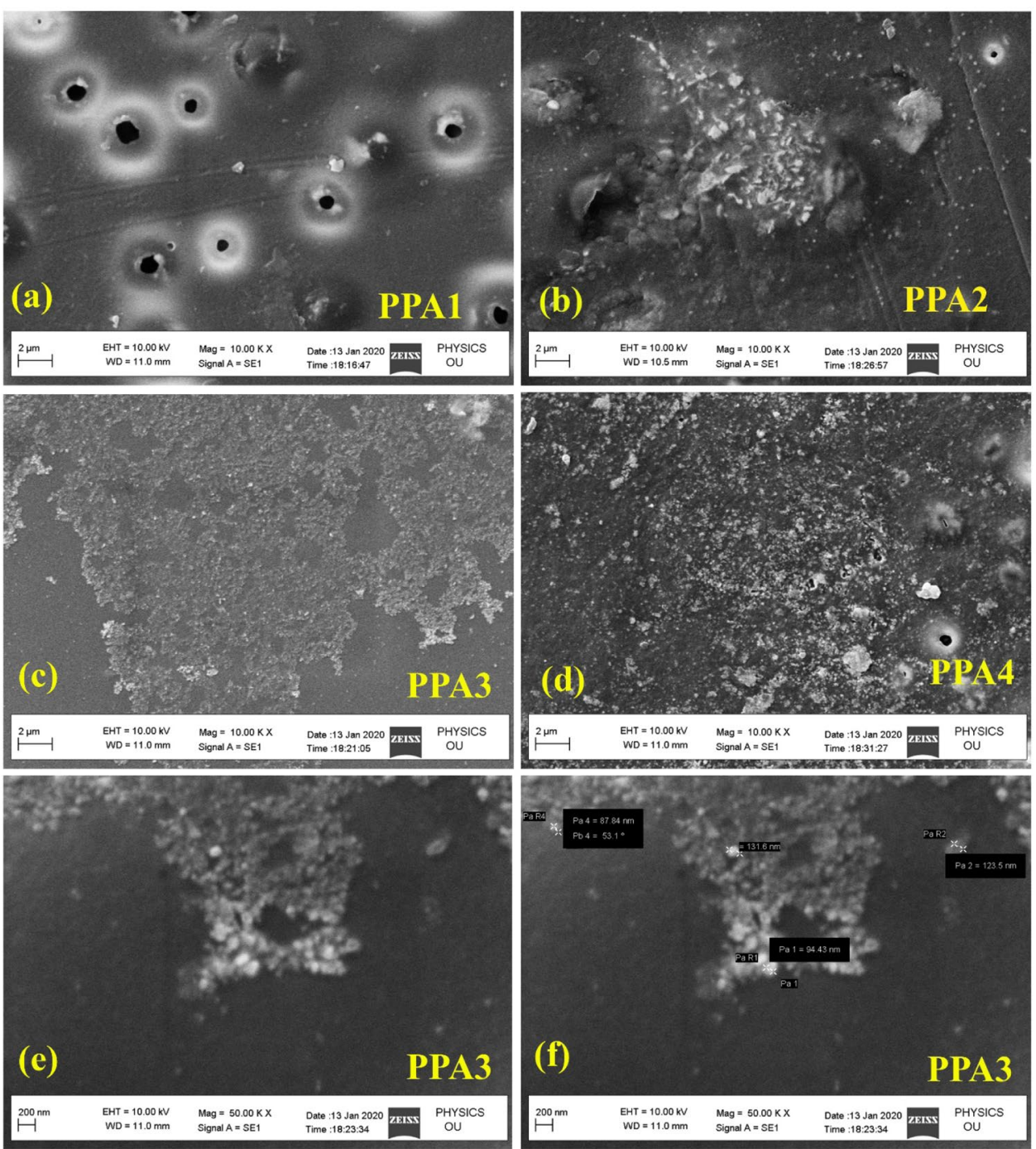

with increasing number of white spots due to the semicrystalline phase of PVdF [29-31] and $\mathrm{AgNO}_{3}$. The further addition of PVdF resulted in the homogeneous distribution of white spots [26] indicating a smooth and porous structure for PPA3 (Fig. 3c) compared to other samples. Figure $3 e$ and $f$ shows the magnified view at $50 \mathrm{KX}$ resolution. Finally, in PPA4 (Fig. 3d), agglomeration of these white spots can be observed.

\subsection{Complex impedance analysis}

The impedance spectra of blend polymer electrolyte systems were presented in the Nyquist plots as given in Fig. 4. Impedance spectroscopy is an effective method for analyzing the process of conduction, transport and involvement of chains of polymer in the charge carrier development phenomenon [32]. The semicircle of high-frequency suggests the electrolyte properties includes bulk resistance and bulk capacitance that arises from the migration of silver ions and polarization of electrolyte respectively. Figure $4 \mathrm{~b}$ depicts the impedance plot of the PPA3 sample at various temperatures. When the temperature increases, the arc intercept of the impedance spectrum will shift towards the center on the $\mathrm{x}$-axis(real), i.e., for the rise in temperature, the bulk resistance $\left(R_{b}\right)$ reduces.

\subsubsection{DC ionic conductivity}

The DC ionic conductivity of the blend polymer electrolyte systems was calculated using the formula $\sigma_{d c}=\frac{t}{A R_{b}}$ [33] where $A$ is the area of cross-section, $t$ is the thickness and $R_{b}$ is the bulk resistance of the electrolyte. The values of $R_{b}$ reduced as the temperature increased. Figure 5 shows Log $\sigma$ vs. 1000/T for various blend polymer electrolytes. With the temperature rise, the conductivity increases with the temperature dependence of Arrhenius [34] type. The increase of DC conductivity with 
Fig. 4 Cole-Cole plots of $(a)$ PPA 1, PPA2, PPA3 and PPA4 at $373 \mathrm{~K}$ (b) PPA3 at various temperatures
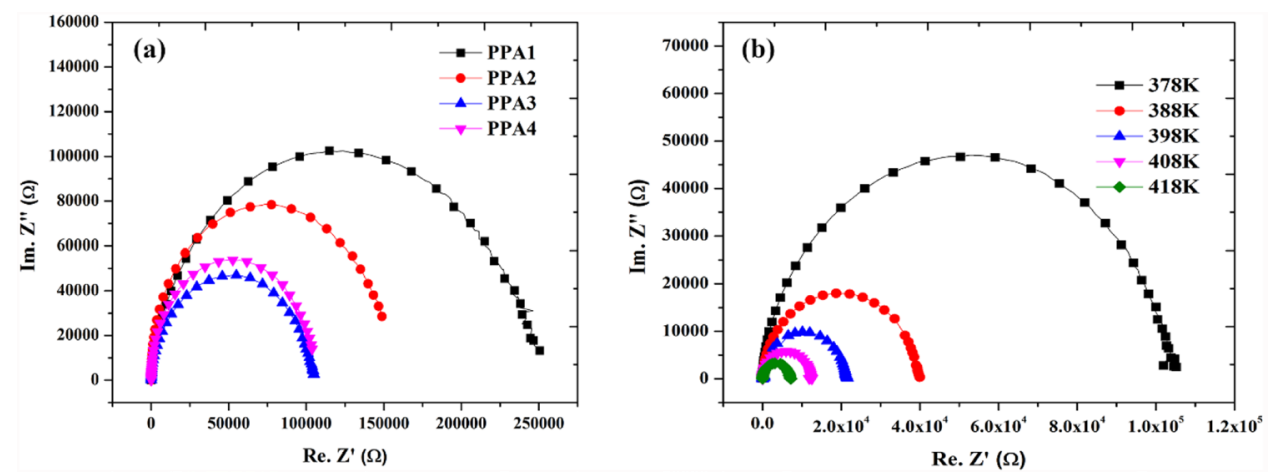

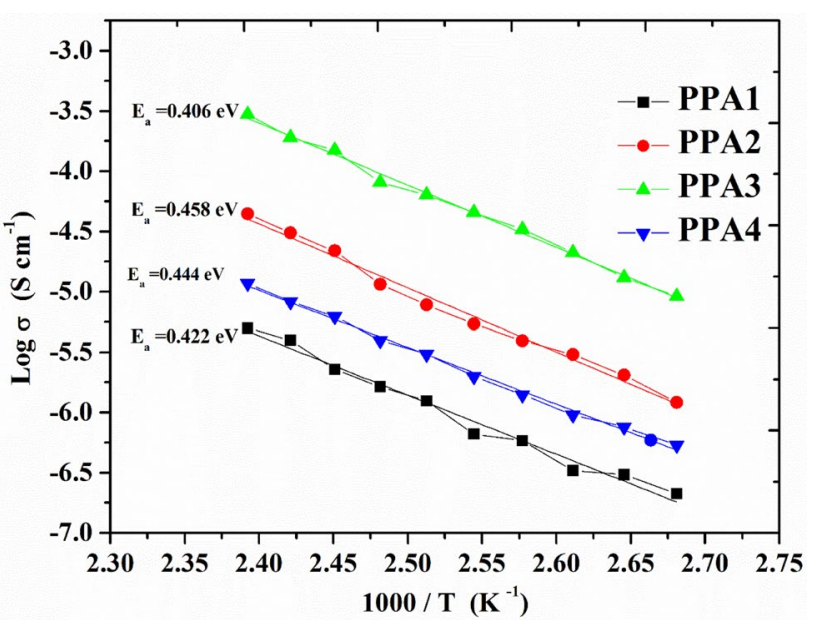

Fig. 5 Log $\sigma$ Vs. 1000/T of PPA1, PPA2, PPA3 and PPA4

temperature can be ascribed to be the dissociation of ions and thus increase the number of charge carriers. The activation energy $\left(E_{a}\right)$ has been calculated for all the samples. The conductivity increases as the host polymer PVdF wt\% increases [35] and maximum conductivity was observed for PPA3, which could be attributed to the hopping phenomenon $[36,37]$ among the coordination sites and polymer segmentation. The conductivity of PPA3
(PMMA/PVdF/AgNO $3: 70 / 30 / 5)$ is $9.13 \times 10^{-6} \mathrm{~S} / \mathrm{cm}$ at $373 \mathrm{~K}$.

\subsubsection{AC Conductivity}

The logarithmic conductivity plots as a variable of frequency displayed in Fig. 6 for different polymer ratio compositions of PMMA and PVdF with $\mathrm{AgNO}_{3}$ salt. This conductivity in polymer electrolytes is a typical phenomenon and this is because of a sudden rise of charge carrier mobility in the complex polymer film. In general, the frequencydependent conductivity could exhibit in three types of dispersion regions with frequency, (1) low-frequency region, which demonstrates the space charge polarization, (2) dc saturation zone in mid-frequency region and (3) dc-to-ac switching at high frequency-zone, which due to the coulombic interaction of charge carrier and disruption within the framework [38, 39]. Figure 6a demonstrates explicitly that the conductivity is almost unchanged in the lowfrequency area, which correlates to conductivity which is independent of frequency. This could be due to the transport of charges through infinite paths [40]. At high frequency, the mobility of charge carriers is greater, so the conductivity increases with frequency. As the PVdF wt\% increases, the conductivity increases due to the availability of mobile species and reaches to the maximum value for
Fig. 6 Frequency dependent conductivity of (a) PPA1, PPA2, PPA3 and PPA4 (b) PPA3 at various temperatures
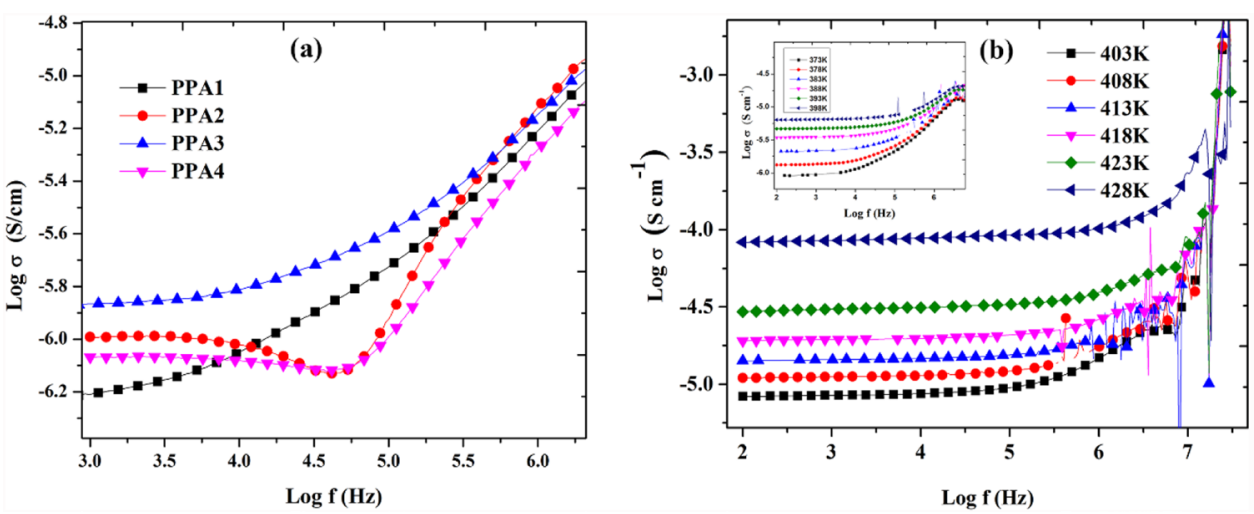

SN Applied Sciences A SPRINGER NATURE journa 
certain concentration, i.e., $30 \mathrm{wt} \%$ of $\mathrm{PVdF}+70 \mathrm{wt} \% \mathrm{PMMA}$ (PPA3). Higher wt\% of PVdF in the electrolyte membrane helps to increase the viscosity, which in effect, reduces the mobility of charge carriers thus decreases the conductivity [41]. The frequency-dependent conductivity for PPA3 sample at various temperatures was shown in Fig. $6 \mathrm{~b}$. As the temperature rises, the frequency scattering gradually moves to the higher frequency zone. At higher frequencies, the transport is controlled by hopping-infinite group contributions. The conductivity increases exponentially and follows Jonscher's power law [42].

$\sigma_{a c}(\omega)=\sigma\left(\omega_{0}\right)+A \omega^{n}$

where $\omega=2 \pi f$ is the angular frequency, $\mathrm{A}$ is the constant and $\mathrm{n}$ is frequency exponent.

\subsubsection{Electric modulus}

The standardized electric modulus can be used to analyze the strategies of relaxation in a broad variety of materials. This relaxation mechanism is attributed to the dispersal of relaxation times, which could be attributed to unevenness, domains of conduction and phase conjunction, etc. The complex electric modulus, $M^{*}=M^{\prime}(\omega)+j M^{\prime \prime}(\omega)$, where $M^{\prime}$ and $M^{\prime \prime}$ are the real and imaginary elements of electric modulus [43]. The following equations can be used to obtain $M^{\prime}$ and $M^{\prime \prime}$.

$M^{\prime}(\omega)=\frac{\varepsilon^{\prime}}{\varepsilon^{\prime 2}+\varepsilon^{\prime \prime 2}} \quad$ and $\quad M^{\prime \prime}(\omega)=\frac{\varepsilon^{\prime \prime}}{\varepsilon^{\prime 2}+\varepsilon^{\prime \prime 2}}$

where $\varepsilon^{\prime}$ and $\varepsilon^{\prime \prime}$ are the real and imaginary parts of dielectric constants. The modulus spectra of blend polymer electrolyte systems have been reported in Fig. 7. A constant value of $M^{\prime}$ at very low frequency is identified to increase with frequency rapidly and reaches saturation at very high frequency which could be noticed from the Fig. 7a. As the $\mathrm{PVdF}$ percentage increases, the $M^{\prime}$ plateau increased in the low-frequency region and decline in peak shifted towards the high-frequency zone, which attributed the interaction between the polymer chains which leads to decrease in relaxation time. The variation of $M^{\prime}$ with frequency at various temperatures of the PPA3 sample was examined and shown in Fig. 7b. The $M^{\prime}$ values declined with rise in temperature at high frequency and the relaxation frequency shifts into high-frequency zone [44]. This may be attributed to rise in the movement of the polymer segmentation due to blending the polymers and charge carriers with the temperature [35]. Figure 8 represents the variation of $M^{\prime \prime}$ with the frequency of the blended polymer electrolyte systems. The broadening and shifting of the peaks were noticed in the blended polymer membranes. The existence
Fig. 7 Variation of Real Electric modulus of (a) PPA1, PPA2, PPA3 and PPA4 (b) PPA3 at various temperatures
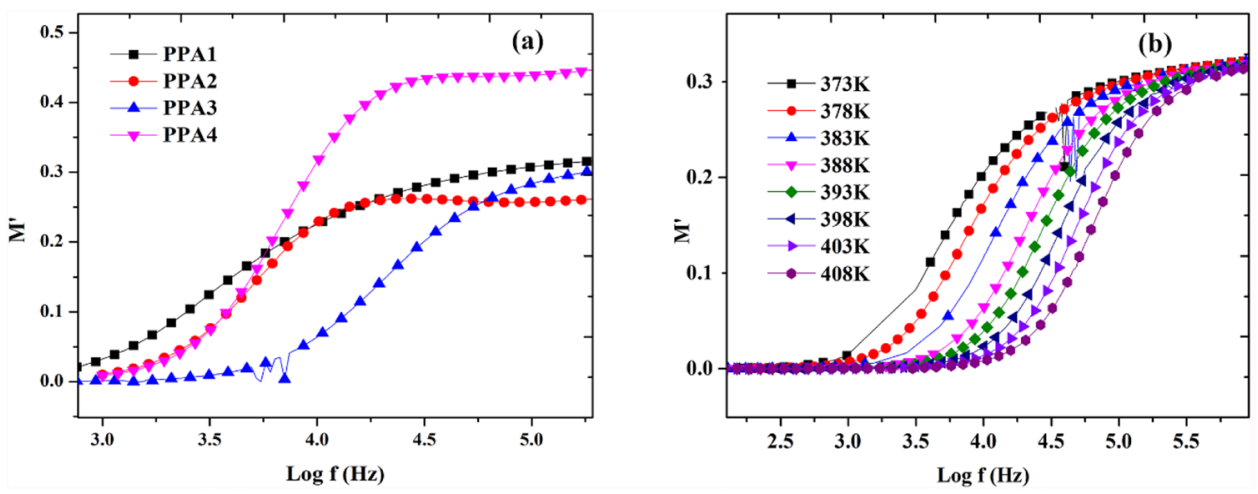

Fig. 8 Variation of imaginary Electric modulus of (a) PPA1, PPA2, PPA3 and PPA4 samples (b) PPA3 at various temperatures
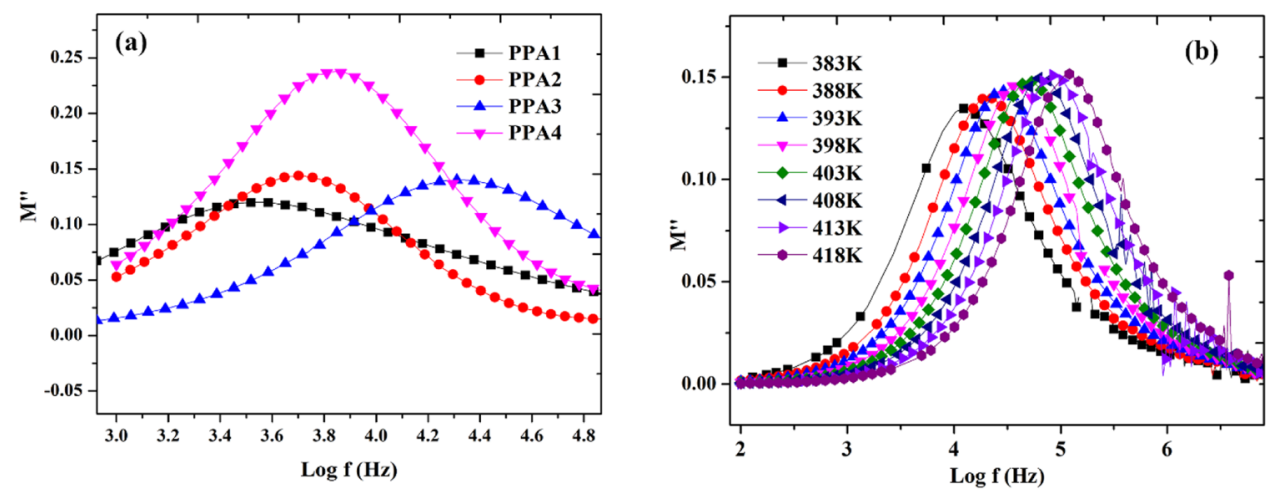
of relaxation peaks in $M^{\prime \prime}$ infers that the films are the great promise of ionic conductors [45]. The investigation of $M^{\prime \prime}$ with frequency at various temperatures was carried out for PPA3 sample and shown in Fig. 8b. The curves of $M^{\prime \prime}$ shows the broad peaks with noticeable asymmetry. It was observed that there is a shift in $M_{\max }^{\prime \prime}$ towards the highfrequency area with an increase in temperature suggests that the increased movement of the charge carriers leading to decrease in relaxation time, which attributes to the fast movement of $\mathrm{Ag}^{+}$ions [46].

\subsubsection{Dielectric studies}

The complex dielectric permittivity $\left(\varepsilon^{*}\right)$ of a material as frequency dependence is given as, $\varepsilon^{*}=\varepsilon^{\prime}(\omega)+j \varepsilon^{\prime \prime}(\omega)$, where $\varepsilon^{\prime}$ is the standard dielectric constant of the sample that determines the quantity of electric energy retained in the substance over every period of the applied alternating field. Figure 9a demonstrates the variation of $\varepsilon^{\prime}$ of the polymer blend electrolyte samples with different $\mathrm{wt} \%$ ratio of PMMA and PVdF. From the figure, it is noticed that the dielectric constant is large at low frequency, which attributes to the tendency of dipoles to align along the field direction $[47,48]$. And also observed that, as the PVdF wt\% increases, $\mathrm{PVdF}$ enables to disperse the ions more and reached to the maximum for PPA3. Figure $9 \mathrm{~b}$ depicts the dielectric constant variation of PPA3 sample at dissimilar temperatures. Due to space charge polarization and electrode polarization, the dielectric constant increases with temperature. It can be clearly shown that there was a high distortion of the permittivity noticed in the low-frequency zone accompanied by an almost frequency independent activity beyond $100 \mathrm{kHz}$. Permittivity values increased with an increase in temperature. Significant improvements in permittivity at the low-frequency area are attributable to space charge and electrode polarization impacts which are responsible for the non-Debye action [40]. Figure 10a represents the imaginary dielectric constant $\left(\varepsilon^{\prime \prime}\right)$ of the blend polymer electrolyte systems with frequency at $373 \mathrm{~K}$. The rise in dielectric constant with temperature [49] corresponds to the rise in density of $\mathrm{Ag}+$-ions and was shown for PPA3 sample in Fig. 10b. The polarization of space charge induces a high dielectric constant at low frequency. It is attributed to the deposition of charges at electrodes and confirms the non-Debye dependence. The higher values of $\varepsilon^{\prime \prime}$ at lower frequency region is due to the movement of free charges within the material, and the prime charge carriers are $\mathrm{Ag}^{+}$-ions in these polymer electrolytes. The disparity of loss tangent with frequency could be used in ionic conductors to illustrate the mechanism of relaxation and for the blended polymer electrolyte systems under the study are shown in Fig. 11a. The loss tangent $(\tan \delta)$ is expressed as $\tan \delta=\frac{\varepsilon^{\prime \prime}}{\varepsilon^{\prime}}$ where $\delta$ is the loss
Fig. 9 (a) Variation of real permittivity of PPA1, PPA2, PPA3 and PPA4 (b) at different temperatures of PPA 3 sample
Fig. 10 (a) Variation of imaginary permittivity of PPA 1 , PPA2, PPA3 and PPA4 (b) at different temperatures PPA3 sample
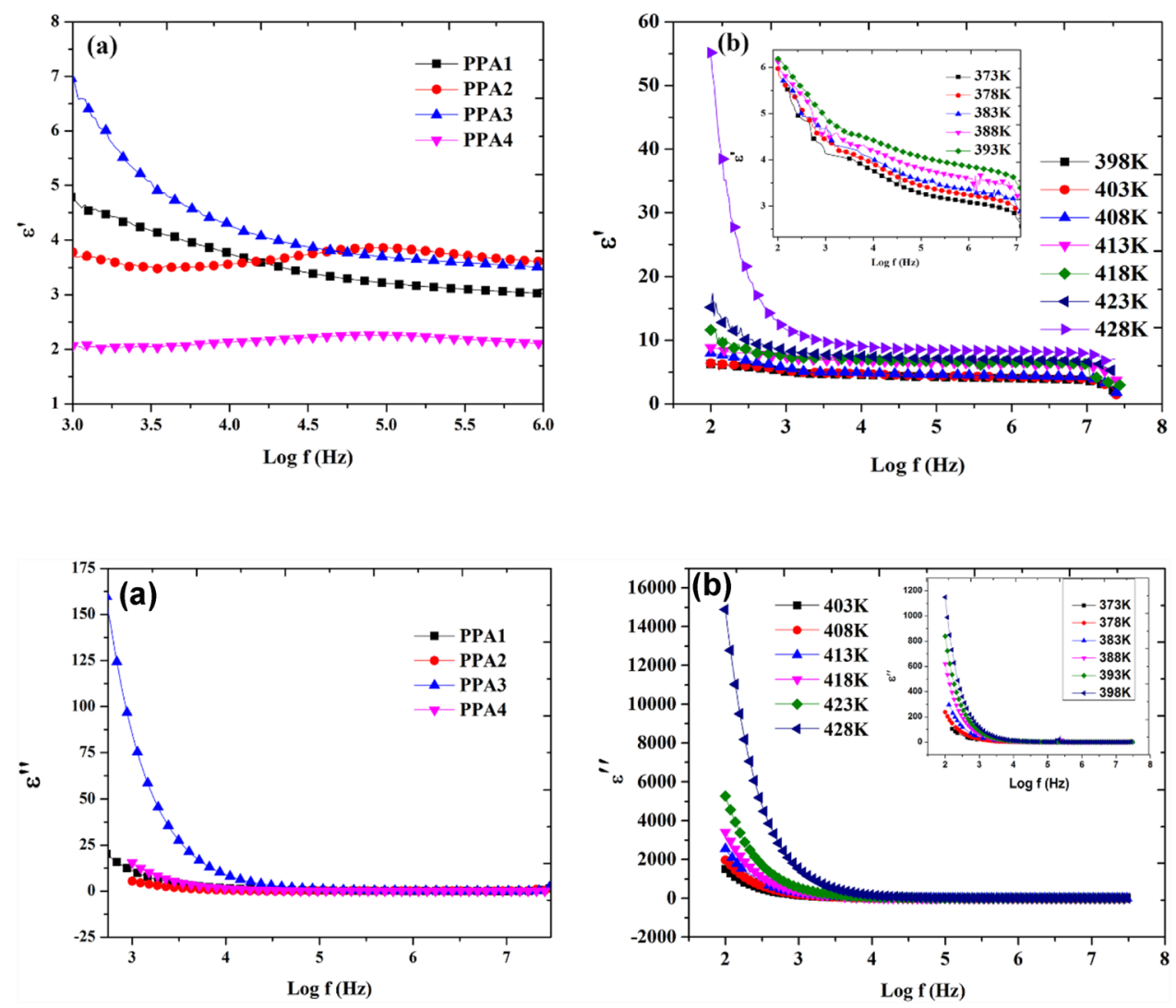

SN Applied Sciences A SPRINGER NATURE journal 
Fig. 11 (a) Frequency dependent dielectric loss tangent of PPA1, PPA2, PPA3 and PPA4 (b) at various temperatures of PPA3

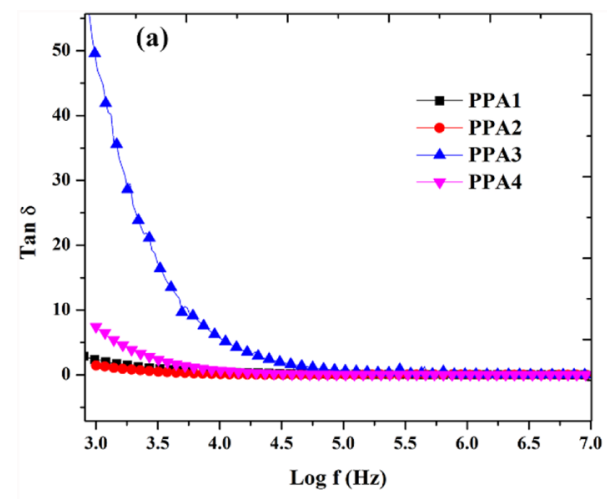

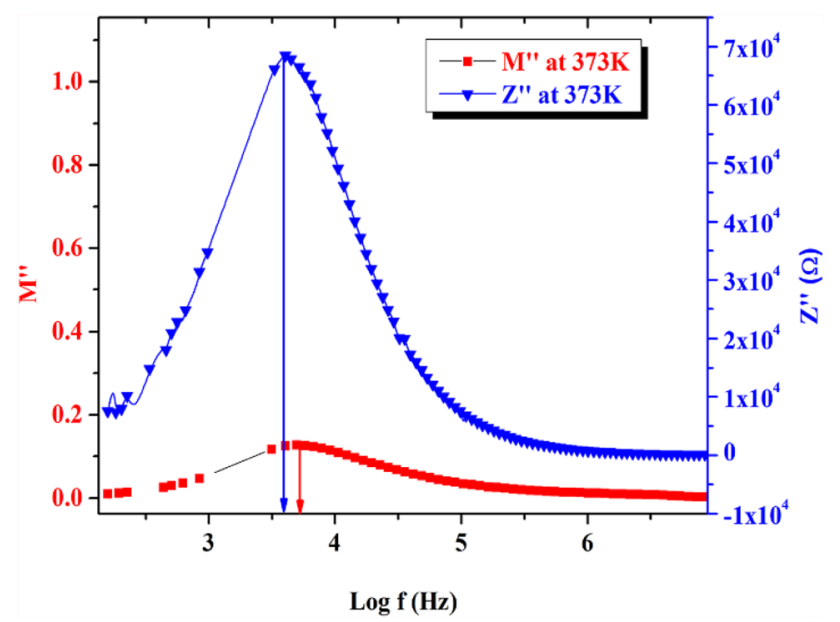

Fig. 12 Variation of $Z^{\prime \prime}$ and $M^{\prime \prime}$ of PPA3 sample with frequency at $373 \mathrm{~K}$

angle [37]. Figure $11 \mathrm{~b}$ exemplifies the dielectric loss tangent with frequency at various temperatures. From the figure, the maximum loss shifts to the high-frequency area when the temperature rises [50] which results in an increase of conductivity due to decreasing relaxation time. The non-Debye behavior of the sample PPA 3 could be understood with the electric impedance and modulus spectrum conveyed in Fig. 12. This could be shown that $Z_{\max }^{\prime \prime}$ and $M_{\max }^{\prime \prime}$ do not coincide at the same frequency [51]. $Z^{\prime \prime}$ widened in lower frequency while $M^{\prime \prime}$ spectrum widened in higher frequency, which indicates the dispersion of relaxation times, i.e., nonDebye activity of electrolyte film.

\section{Conclusions}

PMMA and PVdF based blend polymer electrolytes with $5 \mathrm{wt} \%$ of $\mathrm{AgNO}_{3}$ were prepared by solution cast method by varying the polymers wt $\%$ ratio. The effect of polymer ratio variation on morphology, structural and electrical studies investigated systematically. On the integration of PVdF, the solid polymer electrolyte exhibits improved electrical properties. In specific, 70 wt $\%$ PMMA: 30 wt $\%$ $\mathrm{PVdF}$ with $5 \mathrm{wt} \%$ of $\mathrm{AgNO}_{3}$ has uniform surface and highly amorphous compared with other samples, which has been proven in XRD, SEM and FT-IR analysis. A large plateau region in frequency-dependent conductivity suggests that conductivity is mostly due to ions migration and the sudden rise of ionic conductivity in the high-frequency region is due to the hopping mechanism. Analysis of electric modulus reveals the distribution of relaxation time. Dielectric studies reveal that energy storage $\left(\varepsilon^{\prime}\right)$ at the low-frequency area is higher because of polarization and higher value of energy loss $\left(\varepsilon^{\prime \prime}\right)$ is due to non-Debye type relaxation.

Acknowledgement Authors gratefully thank the Department of Physics, Osmania University, Hyderabad for the experimental facility and UPE-FAR for financial assistance.

\section{Compliance with ethical standards}

Conflict of interest The authors declare that they have no conflict of interest.

\section{References}

1. Fenton DE, Parker JM, Wright PV (1973) Complexes of alkali metal ions with poly(ethylene oxide). Polymers 14:589-589

2. Armand MB (1986) Polymer electrolytes. Ann Rev Mater Res 16:245-261

3. MacCallum JR, Vincent CA (1987) Polymer electrolyte review. Elsevier Applied Science Publisher, London

4. Susan $K$, Fullerton $S$, Janna KM (2010) Structure and mobility of $\mathrm{PEO} / \mathrm{LiClO}_{4}$ solid polymer electrolytes filled with $\mathrm{Al}_{2} \mathrm{O}_{3}$ nanoparticles. J Phys Chem C 114:9196-9206

5. Subba Reddy ChV, Jin AP, Zhu QY et al (2006) Preparation and characterization of (PVP $+\mathrm{NaClO}_{4}$ ) electrolytes for battery applications. Eur Phys J E 19:471-476

6. Jaipal Reddy M, Sreepathi Rao S, Laxminarsaiah E et al (1995) Study of a thin film electrochemical cell based on ( $\left.\mathrm{PVP}+\mathrm{AgNO}_{3}\right)$ electrolyte. Solid State Ion 80(12):93-98 
7. Subba Reddy ChV, Quan-Yao Z, Li-Qiang M et al (2007) Electrochemical studies on PVC/PVdF blend-based polymer electrolytes. J Solid State Electrochem 11:543-548

8. Tripathi SK, Gupta A, Kumari M (2012) Studies on electrical conductivity and dielectric behaviour of PVdF-HFP-PMMA-Nal polymer blend electrolyte. Bull Mater Sci 35:969-975

9. Rajendran S, Sivakumar M, Subadevi R (2004) Investigations on the effect of various plasticizers in PVA-PMMA solid polymer. Mater Lett 58:641-649

10. Sundar M, Selladurai S (2006) Effect of fillers on magnesiumpoly(Ethylene Oxide). Solid Polym Electrolyte lon 12:281-286

11. Amudha S, Austin Sunthathiraraj S, Marimuthu P (2013) Performance characteristic of pyrazole as an effective dopant in a blended polymer electrolyte for nanocrystalline dye sensitized solar cell application. Chem Sci Trans 2:141-146

12. Natarajan R, Subramanian S, Moni P et al (2013) Lithium ion conducting solid polymer blend electrolyte based on bio-degradable polymers. Bull Mater Sci 36:333-339

13. Sundaramahalingam $K$, Muthuvinayagam $M$, Nallamuthu $N$ (2019) AC impedance analysis of lithium ion based PEO:PVP solid polymer blend electrolytes. Polym Sci Ser A 61:565-576

14. Shujahadeen BA, Abdullah OG, Sarkawt AH et al (2017) Effect of PVA blending on structural and ion transport properties of CS:AgNt-based polymer electrolyte membrane. Polym 9:622

15. Shujahadeen BA, Rebar TA, Mariwan AR et al (2017) Polymer blending as a novel approach for tuning the SPR peaks of silver nanoparticles. Polym 9(10):486

16. Hari Sankar M, Ravikant AK et al (2019) Dielectric/ferroelectric properties of ferroelectric ceramic dispersed poly (vinylidene fluoride) with enhanced $\beta$-phase formation. Mater Chem Phys 230:221-230

17. Seyed MS, Qipeng G (2019) Nanophase morphology and crystallization in poly(vinylidene fluoride)/polydimethylsiloxaneblock-poly(methyl methacrylate)-block-polystyrene blends. Polym Int 68:1064-1073

18. Priyanka D, Sengwa RJ (2019) Synergistic effects of salt concentration and polymer blend composition on the crystal phases, dielectric relaxation, and ion conduction in PVDF/PEO/LiCF $\mathrm{SO}_{3}$ solid polymer electrolytes. Ionics 26:2259-2275

19. Sridevi D, Rajendran KV (2009) Synthesis and optical characteristics of ZnO nano crystals. Bull Mater Sci 32(2):165-168

20. Ramesh S, Chiam-Wen L, Morris E et al (2010) Effect of PVC on ionic conductivity, crystallographic structural, morphological and thermal characterizations in PMMA-PVC blend-based polymer electrolytes. Thermochim Acta 511(1,2):140-146

21. Prateek S, Thakur VK, Gupta RK (2016) Recent progress on ferroelectric polymer-based nanocomposites for high energy density capacitors: synthesis, dielectric properties, and future aspects. Chem Rev 116:4260-4317

22. Xiaomei $C$, Tingping $L$, Sun $D$ et al (2017) A critical analysis of the $a, \beta$ and $\gamma$ phases in poly(vinylidene fluoride) using FTIR. RSC adv 7:15382-15389

23. Dhatarwal P, Sengwa RJ (2019) Polymers compositional ratio dependent morphology, crystallinity, dielectric dispersion, structural dynamics, and electrical conductivity of PVDF/PEO blend films. Macromol Res 27:1009-1023

24. Noor SAM, Ahmad A, Talib IA et al (2010) Morphology, chemical interaction and conductivity of a PEO -ENR50 based on solid polymer electrolytes. Ionics 16(2):161-170

25. Rajendran S, Bama VS, Prabhu MR (2010) Effect of lithium salt concentration in PVAc-PMMA based gel polymer electrolytes. Ionics 16(1):27-32

26. Ramesh S, Ang GP (2010) Impedance and FTIR studies on plasticized PMMA-LiN $\left(\mathrm{CF}_{3} \mathrm{SO}_{2}\right)$ nanocomposite polymer electrolytes. Ionics 16(5):465-473
27. Karthik S, Suresh J, Thangaraj V et al (2019) Electrical and mechanical property of the polyvinyl alcohol based solid electrolyte film contains alum. SN Appl Sci 1:1371

28. Sreekanth T, Madhusudhana Reddy T (2014) The effect of nano filler $\mathrm{Al}_{2} \mathrm{O}_{3}$ on $\left(\mathrm{PEO}+\mathrm{KClO}_{4}\right)$ based polymer electrolyte gas sensors. Int J App Phys Math 4(2):99-102

29. Deka M, Kumar A (2010) Enhanced electrical and electrochemical properties of PMMA-clay nanocomposite gel polymer electrolytes. Electrochim Acta 55:1836-1842

30. Shobhna C (2018) Effects of amorphous silica nanoparticles and polymer blend compositions on the structural, thermal and dielectric properties of PEO-PMMA blend based polymer nanocomposites. J Polym Res 25:116

31. Sakthi Velu K, Anandha Raj J, Paruthimal Kalaignan G et al (2018) Preparation and characterizations of PMMA-PVDF based polymer composite electrolyte materials for dye sensitized solar cell. Curr Appl Phys 18:619-625

32. Poonam S, Dinesh Kumar K, Nirali G (2012) Effect of nano-filler on structural and ionic transport properties of plasticized polymer electrolyte. Open J Org Polym Mater 2:38-44

33. Dhatarwal P, Sengwa RJ (2020) Dielectric polarization and relaxation processes of the lithium-ion conducting PEO/PVDF blend matrix-based electrolytes: effect of $\mathrm{TiO}_{2}$ nanofiller. SN Appl Sci 2:833

34. Karthikeyan S, Sikkanthar S, Selvasekarapandian S et al (2016) Structural, electrical and electrochemical properties of polyacryIonitrile-ammonium hexaflurophosphate polymer electrolyte system. J Polym Res 23:51

35. Shanmugaraj P, Swaminathan A, Ravi RK (2019) Preparation and characterization of porous PVdF-HFP/graphene oxide composite membranes by solution casting technique. J Mater Sci Mater Electron 30:20079-20087

36. Kiran Kumar K, Ravi M, Pavani Y et al (2012) Electrical conduction mechanism in $\mathrm{NaCl}$ complexed PEO/PVP polymer blend electrolytes. J Non-Crystalline Solids 358(23):3205-3211

37. Pradhan DK, Choudhary RNP, Samantaray BK (2008) Studies of dielectric relaxation and AC conductivity behavior of plasticized polymer nanocomposite electrolytes. Int J Electrochem Sci 3:597-608

38. Arya A, Sharma AL (2019) Tailoring of the structural, morphological, electrochemical, and dielectric properties of solid polymer electrolyte. lonics 25:1617-1632

39. Manjuladevi R, Thamilselvan $M$, Selvasekarapandian $S$ et al (2017) Mg-ion conducting blend polymer electrolyte based on poly(vinyl alcohol)- poly (acrylonitrile) with magnesium perchlorate. Solid State lon 308:90-100

40. Zaki HM (2005) AC conductivity and frequency dependence of the dielectric properties for copper doped magnetite. Phys B Condens Matter 363:232-244

41. Periasamy P, Tatsumi K, Shikano M et al (1999) An electrochemical investigation on polyvinylidene fluoride-based gel polymer electrolytes. Solid State Ion 126:285

42. Shobhna C, Adam B, Ram Jeewan S et al (2015) Effects of ultrasonic assisted processing and clay nanofiller on dielectric properties and lithium ion transport mechanism of poly(methyl methacrylate) based plasticized polymer electrolytes. J Appl Polym Sci 132(27):42188

43. Ibrahim S, Yasin SMM, Nee NM et al (2012) Conductivity and dielectric behaviour of PEO-based solid nanocomposite polymer electrolytes. Solid State Commun 152:426-434

44. Hossena MB, Akther Hossain AKM (2015) Complex impedance and electric modulus studies of magnetic ceramic $\mathrm{Ni}_{0.27} \mathrm{Cu}_{0.10} \mathrm{Zn}_{0.63} \mathrm{Fe}_{2} \mathrm{O}_{4}$. J Adv Ceram 4(3):217-225

45. Sengwa RJ, Priyanka D, Shobhna C (2018) Study of time-ageing effect on the ionic conduction and structural dynamics in solid 
polymer electrolytes by dielectric relaxation spectroscopy. Solid State lon 324:247-259

46. Kim JS (2001) Electric modulus spectroscopy of lithium tetra borate $\mathrm{Li}_{2} \mathrm{~B}_{4} \mathrm{O}_{7}$ single crystal. J Phys Soc Jpn 70(10):3129-3313

47. Kulshrestha N, Chatterjee B, Gupta PN (2014) Structural, thermal, electrical, and dielectric properties of synthesized nanocomposite solid polymer electrolytes. High Perform Polym Spec Issue Artic 26(6):677-688

48. Singh KP, Gupta PN (1998) Study of dielectric relaxation in polymer electrolytes. Eur Polym J 34:1023-1029

49. Baskaran R, Selvasekarapandian S, Hirankumar G et al (2004) Dielectric and Conductivity relaxations in PVAc based polymer electrolytes. Ionics 10:129-134
50. Baskaran R, Selvasekarapandian S, Kuwata N et al (2006) AC impedance, DSC and FT-IR investigations on (x)PVAc-(1-x)PVdF blends with LiClO4. Mater Chem Phys 98:55-61

51. Dave G, Kanchan DK (2018) Dielectric relaxation and modulus studies of PEO-PAM blend based sodium salt electrolyte system. Indian J Pure Appl Phys 56:978-988

Publisher's Note Springer Nature remains neutral with regard to jurisdictional claims in published maps and institutional affiliations. 